\title{
Student engagement with statistical design of experiments by active learning projects
}

\author{
João, Isabel M., and Silva, João M. ${ }^{\text {a,c }}$ \\ ${ }^{\mathrm{a}}$ Department of Chemical Engineering, ISEL - Instituto Superior de Engenharia de Lisboa, \\ Instituto Politécnico de Lisboa, Portugal, ${ }^{\mathrm{b}}$ CEG-IST, Instituto Superior Técnico, \\ Universidade de Lisboa, Portugal, ${ }^{\mathrm{c} C A T H P R O-C Q E}$, Instituto Superior Técnico, \\ Universidade de Lisboa, Portugal.
}

\begin{abstract}
This paper illustrates the use of design of experiments in an active learning environment in a new Master course in Quality and Environmental Engineering at a higher education institution in Portugal. The study took place in the unit of Advanced Techniques for Quality. The aim of this work is to explain how in an active learning environment the students worked on projects designed to use fractional factorial designs in order to improve a system including the impact that the approach had on students. Twelve master students took part of the classroom projects. Three groups of students worked on projects, created and developed by them contributing to increase their commitment and enthusiasm. In a classroom session the students made a presentation and the results were discussed. Each group also produced a video with the planning and execution of the fractional factorial designs which was helpful to start the debate. The active learning approach required that the students developed their own projects and decide when and how to do the experiments. Taking the responsibility of their activities was very enriching forcing the students to think about the things they did and questioning some of their own decisions.
\end{abstract}

Keywords: Active learning; design of experiments; quality engineering; student-centred learning; factorial design. 


\section{Introduction}

Students' engagement with what they are studying is a key to high quality learning. According to Park (2003) students that actively participate in the learning process tend to understand more, learn more, remember more and enjoy more than those who passively receive the information provided by the teacher. An engaging learning environment have been proved to have strong association with learning outcomes (Schaufeli et al., 2002, Sakurai et al., 2016). The traditional teaching style of lecturers is in several cases verbally orientated, and the students are usually passive except for note-taking. This leads to inattentive and discouraged students losing interest in attending lectures (Prince, 2004). This type of teaching has been changing over the years to make way for active processes in which learners are active sense makers who seek to build coherent and organized knowledge (Mayer, 2004).

The teacher challenge is to stimulate the students to actively engage in the learning process and be able to develop their ideas and be creative, think more critically and also become better prepared to solve problems. The adoption of an active learning approach requires that the teacher adopt a student-centred approach (Wright, 2011) where the teaching and learning emphasize the student activity and responsibility in learning. Some characteristics of these student-centred teaching methods are: (1) the activity and independence of the student, (2) the coaching role of the teacher, and (3) knowledge which is regarded as a tool instead of an aim (Baeten et al., 2010).

The new generation of students that were born in the 1990's have different learning styles and different characteristics e.g. their preference for experiential learning, their digital literacy, the need for interactivity. These are some of the subjects that need to be introduced in the classroom (Skiba \& Barton, 2006). The different learning styles and different expectations of this new generation of students requires that focus is placed in studentcentred approach learning. Accordingly, several teaching methods were developed that indeed emphasized the effectiveness of active learning (Prince, 2004).

Both general higher education literature and statistics education literature highlight the importance of active learning and student engagement. In statistics the learning comes through doing and practice. Many students studying statistics are not doing so out of choice and are not necessarily convinced of its usefulness and they may see it as an imposition, not an interesting learning experience to be applied in their profession. (Bidgood et al., 2010). The introduction of a project chosen by the students engage them in higher order thinking tasks as planification, analysis, synthesis and evaluation. This strategy to promote active learning is defined as an instructional activity involving students doing things and thinking about the things that they are doing. The objective of this paper is to illustrate the use of design of experiments in an active learning environment in a new Master course in Quality 
and Environmental Engineering. In the project the students design experiments evaluate experimental data, and develop the ability to work together in small groups. Studies and reports by the engineering accreditation, ABET suggest that achieving these objectives can help the students in their future engineering profession.

\section{Curricular unit Description}

Advanced Techniques for Quality is a curricular unit of the Master course in Quality and Environmental Engineering at ISEL a Higher Education Engineering School from the Polytechnic Institute of Lisbon. The first edition of the Master course as well as the first edition of the Advanced Techniques for Quality took place in the winter semester of 20152016. The curricular unit was taught twice a week with sessions of 90 minutes each over fifteen weeks covering a semester. The unit covers topics related to product and process design and improvement. The objective is to introduce the experimental design and the types of problems in which designed experiments are useful specially its contribution to the design of more reliable products with greater performance and easier to manufacture. The techniques discussed are of great use in the design and optimization of products and processes. They are used in many industries and are essential for engineers because its correct use is a key factor for better quality and productivity leading to more competitive organizations. The students should acquire skills to demonstrate knowledge of the techniques to evaluate and optimize parameters, namely applying such tools in process/product optimization or in the development of new products and processes. Students should also demonstrate critical and analytical skills by using these techniques. The assessment of the unit includes two short tests during the semester to allow students to demonstrate what they know and if they are achieving the desired learning outcomes. The tests weight a total of $20 \%$ of the final grade and the main objective is to allow the teacher to monitor students' learning along the semester in order to adapt the teaching strategies to the class. Another assessment technique is a summative test that contributes with $40 \%$ to the final grade and occur at the end of the instructional unit and measures the extent to which the students have achieved the desired learning outcomes. The project also weights $40 \%$ of the final grade and is very important because give the students the opportunity to go deeper with the material to set the knowledge they have acquired and also be creative and engaged with the learning process. The project is a group activity and so allows the students to develop the ability to work as a team and also give the students who do not test well the opportunity to demonstrate their skills and acquired knowledge. The project was created as an evaluation activity in order to be engaging and enjoyable for the students. It was our objective to create an evaluative process that would fully engage learners and at the same time could provide us the feedback that we wanted and that we would be able to use. The main objective of the summative test is to have a standardized component of the evaluation 
process so that it will be easier to monitor over time. The introduction of the project, which is a student-centred changing element, let us get feedback from a new perspective with projects chosen and developed by the students.

\section{Design of experiments project}

Central to Advanced Techniques for Quality curricular unit is the students' design of experiments project. The project with an experimental design focus engages students in experimental design methodology. After the development of the project the students should be able to: (1) explain how designed experiments can be used to improve product design and improve process performance, (2) estimate main effects and interactions of factors, (3) understand the factorial and fractional factorial design concept, (4) know how to use the $2^{\mathrm{k}}$ and $2^{\mathrm{k}-\mathrm{p}}$ system of factorial and fractional factorial designs, (5) know how to use the analysis of variance (ANOVA) to analyse data from factorial designs, (6) know how residuals are used for model adequacy checking for factorial designs and (7) know how to construct and interpret contour plots and response surface plots.

The students will consider a designed experiment as a test or series of tests in which purposeful changes are made to the input variables of a process so that they may observe and identify corresponding changes in the output response. To use this approach, it is necessary that the students involved in the experiment have a clear idea in advance of the objective of the experiment, exactly what factors are to be studied, how the experiment is to be conducted, and at least a qualitative understanding of how the data will be analysed. Montgomery (2013) gives an outline of the recommended procedure.

\subsection{Project development}

After the first seven weeks of classes the students start the project. A total of twelve students were grouped in teams of four elements with a total of three groups. The students were asked to pick a subject of their interest and propose the topic, plan the experiments, perform the experiments and analyse the results. Antony and Capon (1998) in their article present a "paper helicopter experiment" which can be easily understood by the students providing a stimulus for the students to think about their own project. The article was delivered to each group of students at the beginning of their work and served as a trigger to the project development. The objective is that students design the experiments to perform without receiving instructions on how to perform the experiments, instead the students have to design the experiments themselves to achieve the specific goals. Each group of students developed each own project and after fourteen weeks since the beginning of the semester they present the project in a session. The discussion of the findings is made with the 
teachers and peers in a session where they have to present the work developed and explain all the steps of the work. The procedure for designing the experiment is presented in fig. 1 .

The students also present the step by step procedure in a video which makes easier the discussion and debate with the professors and colleagues. The production of a video was a requirement that the students should also accomplish. The objective of the teachers with this requirement was to get students energized and engaged in the hands on learning process. The video is also an instructional medium that the students would use to explain the project to peers and to the teachers allowing to a better understanding of the project.

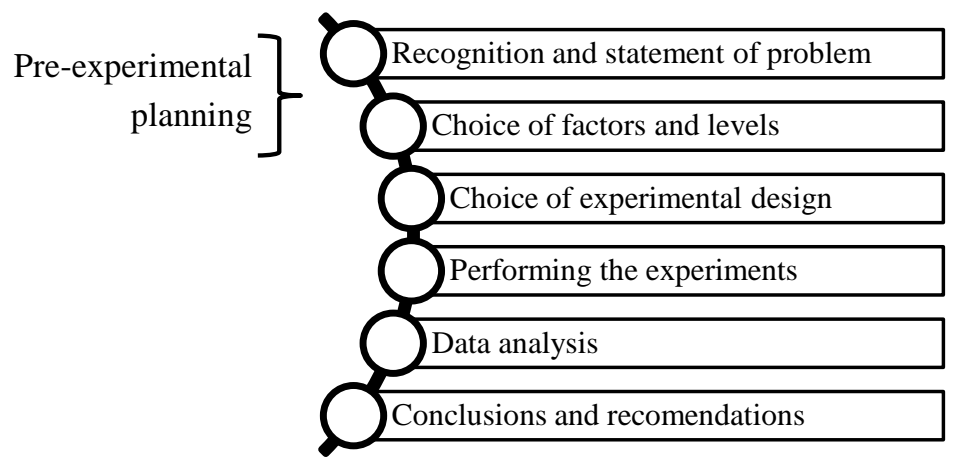

Figure 1. Procedure for designing an experiment.

\subsection{Performing the experimental design}

The students developed their projects in seven weeks. At first the students develop all ideas about the problem and about the specific objectives of the experiment and came with the idea of the project. Then they choose the factors to be varied in the experiment, the ranges over which these factors will be varied, and the specific levels at which runs will be made. In selecting the response variable, the students took into consideration that the variable provides useful information about the problem under study. In the choice of the design the students took in consideration the number of replicates, the selection of a suitable run order for the experimental trials, and the randomization restrictions involved. The students were actively engaged in the learning process and each group developed their own ideas and creative thoughts about the project to develop. Each team's project is identified in fig. 2 . Although in some cases students may have prior expectations regarding the results of the experiments, they are not supposed to make predictions before running the experiments. Only after performing and analysing the experiment the students were able to fit a regression model to the data and use the model to obtain the predicted values at any point in the region of experimentation. 


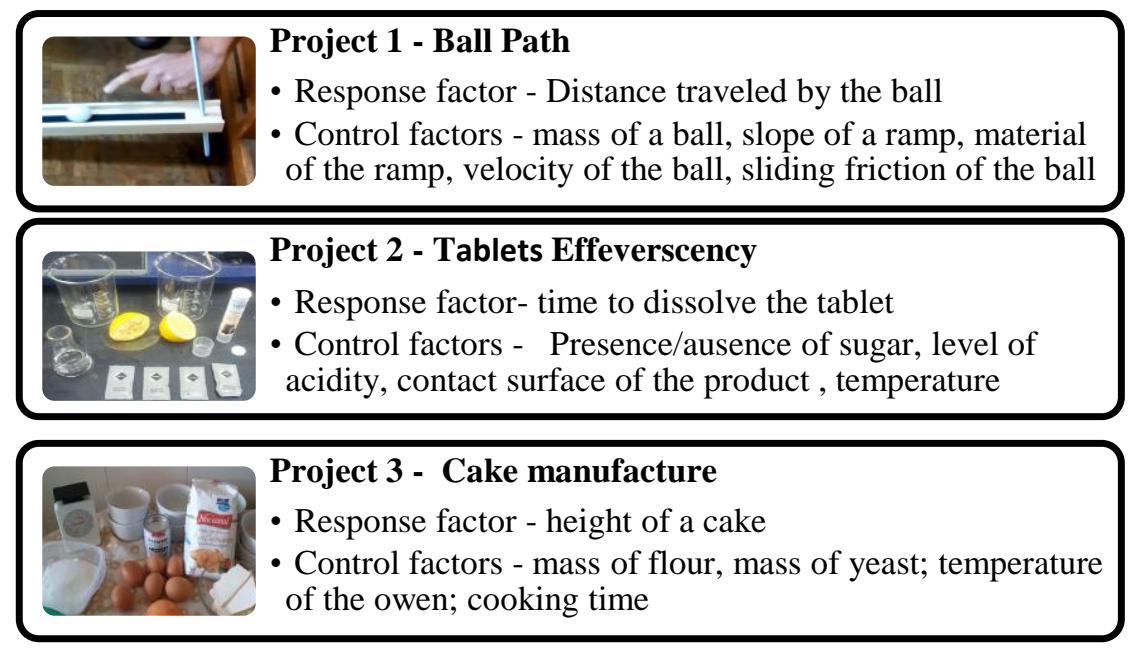

Figure 2.Projects developed by the students.

\section{Students' perceptions about the usefulness of the project}

In one session of 90 minutes the total of twelve students, grouped in teams of four, reflected about the usefulness of the project. In the session the teachers used a verbal open ended questions focusing on the students perception about the usefulness of the project. The teachers used face to face conversation with the teams, unstructured, apparently informal with some pre-determined questions for later in depth analysis. The goal of the project was to help students learn to design experiments and learn how to interpret data and mainly to actively engage students with statistical design of experiments. Some questions were used to guide the conversation:

- What do you think about choosing the topic and develop your own project?

- What do you think about the usefulness of the project to help you to better understand design of experiments methodology?

- Which were the most important things you learned from the project?

- What do you think of the project as an evaluation tool?

- $\quad$ Do you think the project should be kept with this format for the next year?

Qualitative research was used in order to explore the ways in which students think and feel about the project. Rather than producing statistically representative data the exploratory research performed facilitates the identification of general trends regarding students' perceptions.

When questioned about the requirement to choose the topic and develop the project all the students referred that at the beginning they thought it would be difficult without instructions 
but soon became engaged and motivated with their own ideas. When questioned about the usefulness of the project all the students were able to identify the goal and they felt that the work was very useful in order to better understand the steps of design of experiments methodology. The students were asked to describe important things that they learned from the project. All the students found important to figure out things independently without the help of the teacher. They also considered very enriching the fact that it was their responsibility to devise a procedure for the investigation and describe their own design. The identification of the independent and dependent variables in the experiment was also very challenging. The students also found very motivating have to decide about the range of variation of each variable and discuss with colleagues how the range could affect the results of the experiment. One group also referred the usefulness of the graphical methods in the interpretation of the results. All the students referred the difficulty that they faced not particularly in choosing the factors to be varied in the experiment but mostly the ranges over which these factors would be varied, and the specific levels at which the runs would be made. Students mentioned that they did not realized, until they made the project, how important it was having some previous knowledge of the process in order to better select the work levels of the factors. The students found the project enjoyable as an evaluation activity and found important to have a group activity in order to enhance their ability to work as a team. All the students found important that the project should be maintained for the next edition of the course. They also referred that the teachers could introduce the projects developed this year to the next year students because this could work as a trigger to new project ideas.

\section{Conclusions}

We found that students improved on the ability to design an experiment, to devise a procedure to make the experiment, and to analyse the data using appropriate tools. We also found that the students proved to be able in a simple way to communicate the details of the experiment, as well as the difficulties they faced. From the teachers perspective the communication is one of the key roles of the engineer. The quality engineer must be able to explain the results of a complex analysis to a customer with little knowledge on the subject. Teachers must take this into account when devising an assessment strategy for a curricular unit. Another important thing was the enthusiasm of the students when presenting their work and video of their project. Some students brought inclusively samples of their experiments (e.g. cake samples). It was very interesting to note that despite the concepts were previously taught in classes using a combination of techniques (e.g. lectures followed by a practice, case studies, computed guided sessions) the students were much more involved with the project and motivated to put in practice the statistical tools. We think that the "statistical design of experiments thinking" is very important. Although we are in the 
age of computers where they can not only perform all the calculations but also suggest appropriate methods of analysis and in some cases write an automatic report allowing for statistical thinking is much more challenging than assessing the ability to perform routine calculations. The introduction of a student-centred teaching practice with the inclusion of the project allowed the promotion of student's qualities such as intrinsic motivation that stimulate more engaged and deeper learning. The results of the qualitative research of the project were very promising in order to repeat the project approach in the second edition of the master course. It would also be interesting to compare the results of the next year with the results obtained in this first edition of the course as well as with similar courses of different schools.

\section{References}

Antony, J., Capon, N. (1998). Teaching experimental design techniques to industrial engineers. International Journal of Engineering Education, 14(5), 335-343.

Baeten, M., Kyndt, F., Struyven, K, \& Dochy, F. (2010). Using student-centred learning environments to stimulate deep approaches to learning: factors encouraging or discouraging their effectiveness. Educational Research Review, 5, 243-260.

Bidgood, P., Hunt, N., \& Jolliffe, F. (2010). Assessment Methods in Statistical Education: An International Perspective. Chichester, UK: John Wiley \& Sons, Ltd.

Mayer, R. (2004). Should there be a three-strikes rule against pure discovery learning? The case for guided methods of instruction. American Psychologist, 59(1), 14-19.

Montgomery, D.C. (2013). Design and Analysis of Experiments. 8th edition, Singapore, John Wiley \&Sons Inc.

Park, C. (2003). Engaging students in the learning process: the learning journal. Journal of Geography in Higher Education, 27(2), 183-199.

Prince, M. (2004). Does active learning work? A review of the research. Journal of Engineering Education, 93(3), 223-231.

Sakurai, Y., Parpala, A., Pyhälto, K., \& Lindblom-Ylänne, S. (2016). Engagement in learning: a comparison between asian and european international university students. Compare: A journal of Comparative and International Education, 46(1), 24-47.

Schaufeli, W.B., Martinez, I.M., Pinto, A.M., Salanova, M., \& Bakker, A.B. (2002). Burnout and Engagement in University Students: a cross-national study. Journal of Cross-Cultural Psychology, 33(5), 464-481.

Skiba, D.J., \& Barton, A.J. (2006). Adapting your teaching to accommodate the next generation of learners. The Online Journal of Issues in Nursing, 11(2), manuscript 4.

Wright, G.B. (2011). Student-centered learning in higher education. International Journal of Teaching and Learning in Higher Education, 23(3), 92-97. 